\title{
О НЕОДНОЗНАЧНОСТИ ИНТЕРПРЕТАЦИИ ПОЛЯ ТЕМПЕРАТУР ЗАМОРАЖИВАЕМОГО ПОРОДНОГО МАССИВА С ПОМОЩЬЮ СКВАЖИННОЙ ТЕРМОМЕТРИИ
}

\author{
Семин Михаил Александрович1', \\ seminma@inbox.ru
}

\section{Левин Лев Юрьевич1,} aerolog_lev@mail.ru

\author{
Богомягков Александр Васильевич 1 , \\ bavaerolog@gmail.com
}

\author{
Пугин Алексей Витальевич1, \\ lyosha.p@gmail.com \\ 1 Горный институт УрО РАН, \\ Россия, 614007, г. Пермь, ул. Сибирская, 78-а.
}

\begin{abstract}
Актуальность. При проходке вертикальных шахтных стволов с применением специального способа искусственного замораживания пород необходимо осуществлять контроль состояния ледопородного ограждения, фрормируемого вокруг строящегося ствола. Наиболее распространенным и информативным способом экспериментального контроля состояния замороженных пород является на сегодняшний день скважинная термометрия. По данным скважинной термометрии осуществляется калибровка параметров математической модели (теплофизических свойств пород) и интерпретация поля температуры во всем объеме замораживаемого породного массива путем математического моделирования. Калибровка параметров математической модели в определенных условиях может приводить к неоднозначности в определении параметров модели, причина которой в настоящее время не изучена.

Цель настоящей работы состоит в исследовании условий возникновения неоднозначности рассчитанных теплосризических свойств породного массива в результате калибровки математической модели по данным измерений в контрольнотермических скважинах.

Объектом исследования является замораживаемый водонасыщенный породный массив вокруг двух строившихся шахтных стволов калийного рудника Нежинского горно-обогатительного комплекса.

Методы исследования включали в себя сбор и обработку данных скважинной термометрии состояния замораживаемого породного массива, постановку математической модели теплопереноса в замораживаемом породном массиве, численное решение прямой и обратной задач Стефана и теоретическую интерпретацию рассогласований между измеренными и вычисленными температурами пород.

Результаты. Проведены исследования величин рассогласований измеренных и численно рассчитанных температур в контрольно-термических скважинах на фразовой плоскости калибруемых параметров математической модели - теплопроводностей пород в зонах льда и охлаждения. Показано, что минимум функционала рассогласования в определенных условиях перемещается с течением времени или является неединственным. Проведен анализ возникающей неоднозначности на базе упрощенной математической модели теплового баланса на границе фронта фазового перехода. Получено, что на стадии активного замораживания возможно недостоверное определение теплопроводности в зоне льда из-за высокого градиента температуры в массиве вблизи контрольно-термических скважин и погрешности скважинной инклинометрии. На стадии пассивного замораживания возможно недостоверное определение обеих теплопроводностей, так как решение задачи зависит преимущественно от их соотношения.
\end{abstract}

\section{Ключевые слова:}

Искусственное замораживание пород, ледопородное ограждение, контрольно-термические скважины, обратная задача Стефана, математическое моделирование, теплопроводность пород.

\section{Введение}

Строительство стволов шахт и тоннелей метрополитенов в сложных гидрогеологических условиях осуществляется с использованием специальных способов и, в частности, способа искусственного замораживания пород $[1,2]$. Целью искусственного замораживания породного массива является формирование ледопородного ограждения (ЛПО) заданной толщины, достаточной для того, чтобы воспринять давление окружающих незамороженных горных пород и содержащейся в них поровой воды, не допустить проникновения подземных вод в строящуюся горную выработку.
Действующие «Правила безопасности ...» обязывают организовывать систематический контроль состояния замороженных пород [3]. Согласно [4], наблюдение за процессом замораживания и состоянием ЛПО должно осуществляться с использованием контрольных скважин: гидрогеологических и термометрических. Термометрия в контрольнотермических (КТ) скважинах на сегодня является основным и наиболее информативным способом анализа фактических параметров ЛПО - этот экспериментальный способ применяется при строительстве стволов шахт и тоннелей метрополитенов как на территории России [5-7], так и за рубежом [8-11]. 
Экспериментальный контроль состояния ЛПО, как правило, сопровождается теоретическими расчетами времени формирования ЛПО заданной толщины [12-14]. В ряде практических случаев экспериментальный и теоретический методы используются взаимосвязано: в этом случае экспериментально измеренные температуры породного массива в КТ скважинах применяются для параметризации математической модели замораживаемого породного массива, а последняя используется для определения поля температур во всем объеме породного массива, подверженного тепловому воздействию от системы замораживания [15-20]. За рубежом такой подход чаще всего называется обратным анализом $[15,16]$, в то время как в России - решением коэффициентной обратной задачи Стефана $[17,18]$, или просто обратной задачи [19]. Впервые такой подход был применен в работе [19] и заключался в калибровке значений теплопроводностей породного массива на предмет наилучшего соответствия вычисленных и измеренных температур в КТ скважинах. Выбор теплопроводностей обосновывался низкой точностью их определения по результатам лабораторных испытаний образцов керна пород.

Как было показано в [17], в ряде практических ситуаций может существовать более одного решения обратной задачи Стефана. Физически это означает, что теплофизические свойства породного массива могут неоднозначно определяться по данным измерений температуры в КТ скважинах. В такой ситуации высок риск неправильного выбора теплофизических параметров породного массива из полученного множества решений обратной задачи. Это неблагоприятно, т. к. в этой ситуации может возникать неконтролируемая погрешность при теоретическом определении температурного поля породного массива на пространственном удалении от КТ скважин, а также при прогнозировании искусственного замораживания пород в будущем без опоры на данные скважинной термометрии.

По этой причине важно определить условия, при которых возникает неоднозначность определения теплофизических свойств породного массива в результате калибровки математической модели по данным измерений в КТ скважинах. В существующей научной литературе обозначенный частный вопрос остается на сегодняшний день не освещенным.

Настоящая статья посвящена анализу условий возникновения неоднозначности в определении теплофизических свойств породного массива по данным измерений в КТ скважинах. Анализ проводился для реальных данных скважинной термометрии, полученных в процессе контроля формирования ЛПО вокруг строившихся вертикальных шахтных стволов рудника Нежинского горно-обогатительного комплекса в республике Беларусь.

\section{Математическая модель}

замораживаемого породного массива

Рассматривалась задача об искусственном замораживании породного массива контуром вертикальных замораживающих скважин. Замораживаемый объем породного массива делился на несколько горизонтальных слоев, каждый из которых рассматривался в отдельности (рис. 1).

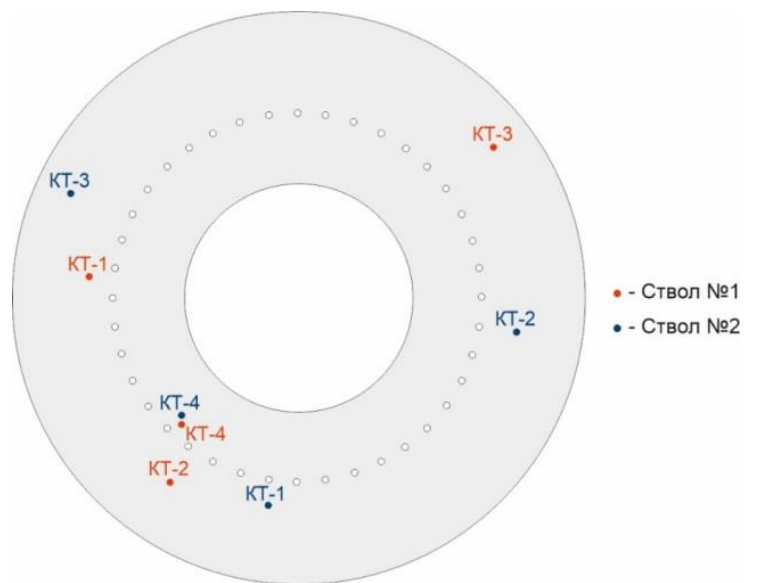

Рис. 1. Геометрия расчетной области: горизонтальный слой породного массива с контуром замораживающих скважсин и КТ скважинами для ствола № 1 (красный цвет) и ствола № 2 (синий иввет)

Fig. 1. Geometry of the domain: a horizontal layer of the rock mass with the contour of freezing boreholes and control boreholes for shaft no. 1 (red) and shaft no. 2 (blue)

Теоретический анализ теплопереноса в каждом слое влажного породного массива при его искусственном замораживании проводился посредством решения двумерной нестационарной задачи Стефана в обобщенной постановке [21]. При математической постановке задачи Стефана для каждого слоя пород принимались следующие допущения:

1) однородность и изотропность теплофизических свойств породного массива в зонах льда и охлаждения;

2) вертикальный тепловой поток отсутствует; распределение температуры считается однородным по всей толщине слоя;

3) миграция поровой воды не рассматривается;

4) породный массив является полностью насыщенным влагой, а его поровое пространство не содержит газовых компонент;

5) локальное тепловое равновесие между различными фазами (сухой скелет, поровая вода, поровый лед);

6) фазовый переход поровой влаги происходит полностью в некотором конечном интервале температур $\left[T^{(s d)} ; T^{(l q)}\right]$.

При задании положений замораживающих и КТ скважин учитывались их фактические горизонтальные отклонения от проектных положений, полученные с помощью скважинной инклинометрии. На рис. 1 , схематично иллюстрирующем контур замораживания, отклонения скважин не показаны.

С учетом сделанных допущений задача Стефана в обобщенной постановке в энтальпийном виде записывается следующим образом [17]:

$$
\frac{\partial H_{i}}{\partial t}=\frac{\partial}{\partial x}\left(\lambda_{i} \frac{\partial T_{i}}{\partial x}\right)+\frac{\partial}{\partial y}\left(\lambda_{i} \frac{\partial T_{i}}{\partial y}\right),
$$




$$
\begin{aligned}
& \lambda_{i}=\left(\lambda_{i}^{(l q)}\right)^{1-\varphi_{i}} \cdot\left(\lambda_{i}^{(s d)}\right)^{\varphi_{i}}, \\
& H_{i}\left(T_{i}\right)=\left\{\begin{array}{cc}
\rho_{i}^{(l q)} c_{i}^{(l q)}\left(T_{i}-T_{i}^{(l q)}\right)+\rho_{i}^{(l q)} w_{i} L, & T_{i}^{(l q)} \leq T ; \\
\rho_{i}^{(l q)} w_{i} L \cdot\left(1-\varphi_{i}\right), & T_{i}^{(s d)} \leq T_{i}<T_{i}^{(l q)} ; \\
\rho_{i}^{(s d)} c_{i}^{(s d)}\left(T_{i}-T_{i}^{(s d)}\right), & T_{i}<T_{i}^{(s d)},
\end{array}\right. \\
& \varphi_{i}\left(T_{i}\right)=\left\{\begin{array}{cc}
0, & T_{i}^{(l q)} \leq T ; \\
\left(T_{i}-T_{i}^{(l q)}\right) /\left(T_{i}^{(s d)}-T_{i}^{(l q)}\right), & T_{i}^{(s d)} \leq T_{i}<T_{i}^{(l q)} ; \\
1, & T_{i}<T_{i}^{(s d)},
\end{array}\right. \\
& {\left.\left[\lambda_{i} \frac{\partial T_{i}}{\partial n}-\alpha\left(T_{f b}(t)-T_{i}\right)\right]\right|_{\Omega f b}=0,} \\
& \alpha=\frac{\lambda_{b}}{2 r_{f b} \xi} \mathrm{Nu}=\frac{\lambda_{b}}{2 r_{f b} \xi} \cdot 1,55\left(\mathrm{Pe} \frac{2 r_{f b} \xi}{h}\right)^{0,33}, \\
& \mathrm{Pe}=\frac{2 r_{f b} \xi \rho_{b} c_{b} V}{\lambda_{b} h}, \\
& \left.T_{i}\right|_{\Omega \text { out }}=T_{0 i}, \\
& \left.T_{i}\right|_{t=0}=T_{0 i},
\end{aligned}
$$

где индекс $i$ соответствует номеру слоя породного массива; $H$ - удельная энтальпия породного массива, Дж/м ${ }^{3} ; x, y-$ физические координаты, м; $t$ - физическое время, с; $\lambda^{(l q)}, \lambda^{(s c)}-$ теплопроводности массива в зонах охлаждения и льда соответственно (в смысле Н.Г. Трупака $[1]), \mathrm{BT} /\left(\mathrm{m}^{\circ}{ }^{\circ} \mathrm{C}\right) ; c^{(l q)}, c^{(\text {sd })}-$ удельные теплоемкости массива в зонах охлаждения и льда соответственно, Дж/(кг $\left.{ }^{\circ} \mathrm{C}\right) ; \rho^{(l q)}, \rho^{(s d)}-$ плотности массива в зонах охлаждения и льда соответственно, кг $/ \mathrm{M}^{3}$; $T^{(l q)}$ - температура начала кристаллизации поровой воды (температура ликвидуса), ${ }^{\circ} \mathrm{C} ; T^{(s d)}$ - температура начала плавления порового льда (температура солидуса), ${ }^{\circ} \mathrm{C} ; \varphi$ - объемная доля льда в порах породного массива (льдистость), $\mathrm{m}^{3} / \mathrm{m}^{3} ; L$ - удельная теплота кристаллизации воды, Дж/кг; $w$ - влажность породного массива (в смысле Н.А. Цытовича [22]), кг/кг; $T_{f b}(t)$ - температура хладоносителя, ${ }^{\circ} \mathrm{C} ; T_{0}$ - температура непотревоженного породного массива на удалении от контура замораживания, ${ }^{\circ} \mathrm{C} ; \alpha-$ коэффициент теплоотдачи на границе с замораживающими скважинами, $\mathrm{BT} /\left(\mathrm{M}^{2} .{ }^{\circ} \mathrm{C}\right) ; \mathrm{Nu}$ - число Нуссельта; $\mathrm{Pe}-$ число Пекле; $\lambda_{b}$ - теплопроводность хладоносителя, $\mathrm{BT} /\left(\mathrm{M}^{\circ}{ }^{\circ} \mathrm{C}\right) ; c_{b}-$ удельная теплоемкость хладоносителя, Дж/(кг $\left.{ }^{\circ} \mathrm{C}\right) ; \rho_{b}-$ плотность хладоносителя, кг $/ \mathrm{M}^{3} ; r_{f b}$ радиус замораживающих колонок, м; $\xi=0,29$ - безразмерный коэффициент, учитывающий то, что восходящий поток хладоносителя занимает только часть сечения замораживающей колонки; $V$ - средняя скорость хладоносителя в замораживающей колонке, м/с; $h$ - высота замораживающих колонок, м; $\Omega_{f b}$ - граница с замораживающими скважинами; $\Omega_{\text {out }}-$ внешняя граница области моделирования; $n$ - координата вдоль нормали к границе $\Omega_{f b}$, м.

Математическая модель реализована численно с помощью метода конечных разностей на полярной сетке, состоящей из трех кольцевых блоков. Между кольцевыми блоками с различной густотой сетки задавалось условие интерфейса (равенство температур и тепловых потоков). Размер ячеек сетки определялся на основании предварительного моделирования с целью обеспечения независимости решения от способа разбиения. На границе с замораживающими колонками задавалось сгущение конечно-разностной сетки для корректного моделирования высоких градиентов температуры в начальный период замораживания (размер ячеек на границе с колонками составил не более $1 \mathrm{~cm}$ ). На внешней границе расчетной области размер ячеек равен около 1,50 м. Количество узлов в итоговом варианте сетки, принятой для расчетов, составило 29504. Использовалась центральная по пространству и верхняя по времени разностная схема для уравнения диффузии. Алгоритмизация осуществлялась в среде MS Visual Studio. Моделирование проводилось для двух слоев горных пород в интервале замораживания пород для условий строящихся стволов рудника Нежинского горно-обогатительного комплекса - слоя мела, залегающего в интервале глубин [86,5 м; 113 м], и слоя песка, залегающего в интервале глубин [119 м; 147 м]. Теплофизические свойства

\begin{tabular}{|c|c|c|c|c|}
\hline \multirow{3}{*}{$\begin{array}{c}\text { Свойство } \\
\text { Property }\end{array}$} & \multicolumn{4}{|c|}{ Значение/Value } \\
\hline & \multicolumn{2}{|c|}{ Ствол № 1/Shaft no. 1} & \multicolumn{2}{|c|}{ Ствол № 2/Shaft no. 2} \\
\hline & $\begin{array}{c}\text { Мел } \\
\text { Chalk }\end{array}$ & $\begin{array}{c}\text { Песок } \\
\text { Sand }\end{array}$ & $\begin{array}{c}\text { Мел } \\
\text { Chalk }\end{array}$ & $\begin{array}{c}\text { Песок } \\
\text { Sand }\end{array}$ \\
\hline $\begin{array}{l}\lambda^{(s d)}, \mathrm{BT} /\left(\mathrm{M}^{\circ}{ }^{\circ} \mathrm{C}\right) \\
\lambda^{(s d)}, \mathrm{W} /\left(\mathrm{m} \cdot{ }^{\circ} \mathrm{C}\right)\end{array}$ & 2,46 & 4,3 & 2,46 & 4,4 \\
\hline $\begin{array}{l}\lambda^{(l q)}, \mathrm{BT} /\left(\mathrm{M}^{\cdot \circ} \mathrm{C}\right) \\
\lambda^{(l q)}, \mathrm{W} /\left(\mathrm{m}^{\circ}{ }^{\circ} \mathrm{C}\right)\end{array}$ & 1,67 & 2,64 & 1,67 & 3 \\
\hline $\begin{array}{l}\rho^{(s d)}, \mathrm{\kappa} / \mathrm{M}^{3} \\
\rho^{(s d)}, \mathrm{kg} / \mathrm{m}^{3}\end{array}$ & 1870 & 1840 & 1870 & 2020 \\
\hline $\begin{array}{l}\rho^{(l q)}, \mathrm{\kappa} \Gamma / \mathrm{M}^{3} \\
\rho^{(l q)}, \mathrm{kg} / \mathrm{m}^{3}\end{array}$ & 1870 & 1840 & 1870 & 2020 \\
\hline $\begin{array}{l}\left.c^{(s d)}, \text { Дж/(кг }{ }^{\circ} \mathrm{C}\right) \\
c^{(s d)}, \mathrm{J} /\left(\mathrm{kg} \cdot{ }^{\circ} \mathrm{C}\right)\end{array}$ & 1164 & 900 & 1164 & 896 \\
\hline $\begin{array}{l}\left.c^{(l q)}, \text { Дж/(кГ } \cdot{ }^{\circ} \mathrm{C}\right) \\
c^{(l q)}, \mathrm{J} /\left(\mathrm{kg} \cdot{ }^{\circ} \mathrm{C}\right)\end{array}$ & 1720 & 1712 & 1720 & 1000 \\
\hline $\begin{array}{l}w, \mathrm{\kappa} \Gamma / \mathrm{\kappa г} \\
w, \mathrm{~kg} / \mathrm{kg}\end{array}$ & 0,163 & 0,086 & 0,157 & 0,09 \\
\hline$T^{(s d)},{ }^{\circ} \mathrm{C}$ & $-0,08$ & $-0,4$ & $-0,08$ & $-0,3$ \\
\hline$T^{(l q)},{ }^{\circ} \mathrm{C}$ & $-0,58$ & $-0,9$ & $-0,58$ & $-0,8$ \\
\hline $\begin{array}{l}L, \text { Дж/кГ } \\
L, \mathrm{~J} / \mathrm{kg} \\
\end{array}$ & 330000 & 330000 & 330000 & 330000 \\
\hline$T_{0},{ }^{\circ} \mathrm{C}$ & 10,3 & 10,6 & 10,3 & 10,4 \\
\hline
\end{tabular}
этих слоев, взятые из отчета по инженерногеологическим изысканиям для рассматриваемого участка, сведены в табл. 1.

Таблица.1. Теплофизические свойства исследуемых слоев породного массива

Table 1. Thermophysical properties of the studied layers of the rock mass

В табл. 2 представлены геометрические параметры задачи. На рис. 2 представлены временные диаграммы температуры и расхода хладоносителя в замораживающих колонках. В качестве хладоносителя использовался 25\%-й раствор $\mathrm{CaCl}_{2}$, теплофизические свойства которого взяты из [23]: $\rho_{b}=1280 \mathrm{\kappa г} / \mathrm{m}^{3}$, $c_{b}=2659$ Дж/(кг $\left.{ }^{\circ} \mathrm{C}\right), \lambda_{b}=0,49 \mathrm{BT} /\left(\mathrm{м}^{\circ}{ }^{\circ} \mathrm{C}\right)$. Максимальный расход хладоносителя в системе размораживания $\left(263 \mathrm{~m}^{3} / \mathrm{c}\right)$ соответствует средней скорости хладоноси- 
теля в замораживающей колонке, равной около 0,22 м/с, и числу Рейнольдса, равному примерно 580, согласно [24], в этом случае реализуется ламинарный режим течения $(\operatorname{Re}<2300)$. Формулы (6), (7) для расчета коэффициента теплоотдачи соответствуют ламинарному режиму течения.

Таблица 2. Геометрические параметры задачи

Table 2. Geometric parameters

\begin{tabular}{|l|c|}
\hline \multicolumn{1}{|c|}{$\begin{array}{l}\text { Параметр } \\
\text { Рarameter }\end{array}$} & $\begin{array}{c}\text { Значение } \\
\text { Value }\end{array}$ \\
\hline $\begin{array}{l}\text { Радиус кругового сектора (расчетной области), м } \\
\text { Radius of the computational domain, m }\end{array}$ & 31 \\
\hline $\begin{array}{l}\text { Среднее расстояние от центра кругового секто- } \\
\text { ра до центра замораживающей колонки, м } \\
\text { Radius of the freezing contour, m }\end{array}$ & 8 \\
\hline $\begin{array}{l}\text { Paдиус замораживающей колонки, м } \\
\text { Freezing pipe radius, m }\end{array}$ & 0,073 \\
\hline $\begin{array}{l}\text { Количество замораживающих колонок } \\
\text { Number of freezing pipes }\end{array}$ & 40 \\
\hline $\begin{array}{l}\text { Глубина замораживающих колонок, м } \\
\text { Depth of freezing pipes, m }\end{array}$ & 160 \\
\hline
\end{tabular}

Контроль состояния замороженных пород на каждом из двух строящихся стволов осуществлялся с помощью четырех КТ скважин, местоположения которых показаны на рис. 1. Абсолютная погрешность измерений в скважинах составляла $1{ }^{\circ} \mathrm{C}$ с разрешающей способностью 0,5 м. Измеренные температуры по глубине КТ скважин, эпюры которых представлены на рис. 3, использовались для калибровки теплофизических свойств породного массива (теплопроводностей в зонах льда и охлаждения, влажности), Калибровка теплофизических свойств породного массива производилась посредством минимизации функ- ционала $I$ рассогласования температур на контрольных скважинах, измеренных экспериментально $\left(T_{i}^{(c)}\right)$ и рассчитанных теоретически $\left(T_{i}\right)$, путем решения прямой задача Стефана:

$$
I=\sqrt{\frac{1}{N_{C}} \frac{1}{\Delta T^{2}} \sum_{i=1}^{N_{C}}\left(T_{i}-T_{i}^{(c)}\right)^{2}},
$$

где $N_{C}-$ количество контрольных скважин; $\Delta T=\max _{t \in\left[0, t_{\text {end }}\right]}\left(T_{0}-T_{f r}(t)\right)$ - характерная разница температур в рассматриваемой задаче, ${ }^{\circ} \mathrm{C} ; t_{\text {end }}$ - время моделирования, сут.

Полученные в результате минимизации функционала I (10) теплофизические свойства породного массива по сути являются эффективными теплофизическими свойствами, в которые неявным образом «зашиваются» другие, неучтенные в модели физические процессы и факторы - неоднородность породного массива, погрешность процедуры инклинометрии замораживающих и КТ скважин, теплоперенос вследствие возможной миграции влаги и др.

\section{Результаты моделирования}

В работе проводились исследования вида функционала $I$ в фазовом пространстве калибруемых параметров задачи $\left(\lambda^{(s d)}\right.$ и $\left.\lambda^{(l q)}\right)$. В результате проведенного многопараметрического численного моделирования замораживания породного массива при различных значениях теплопроводностей $\lambda^{(s d)}$ и $\lambda^{(l q)}$ получены изолинии функционала $I$ и положения его минимума в фазовом пространстве теплопроводностей в различные моменты времени для двух стволов и двух рассматриваемых слоев пород (рис. 4-6). a/a)

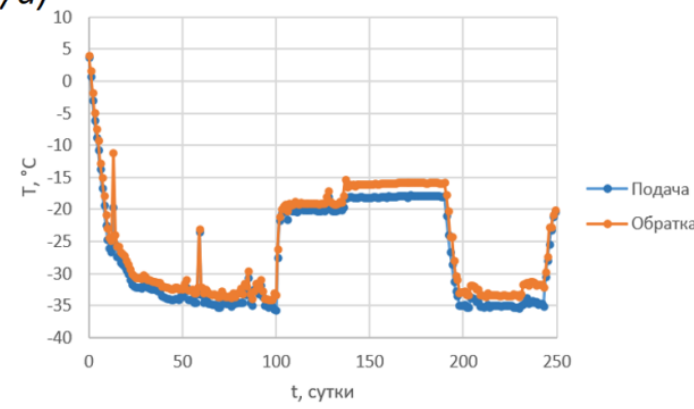

B/c)

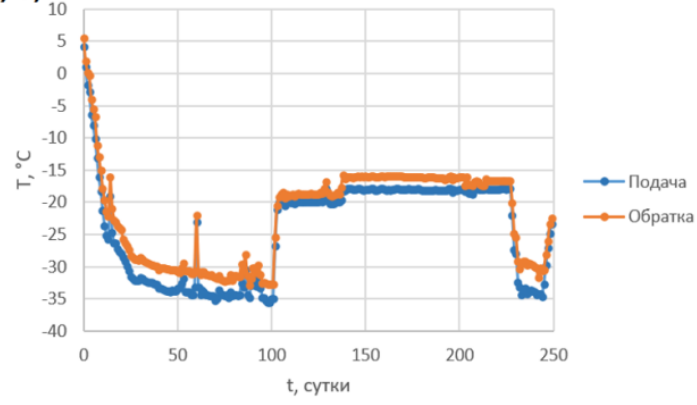

б/b)

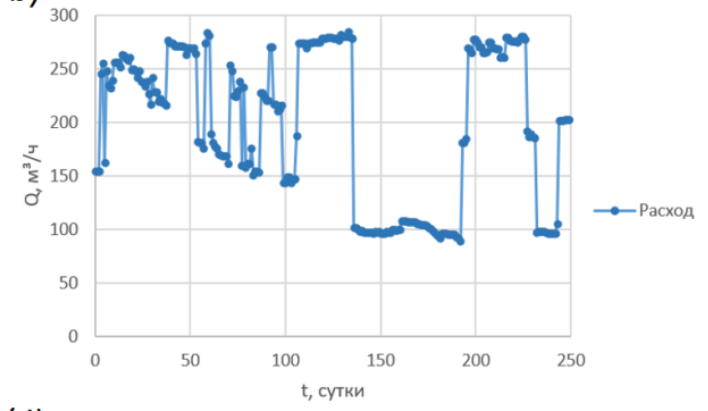

2/d)

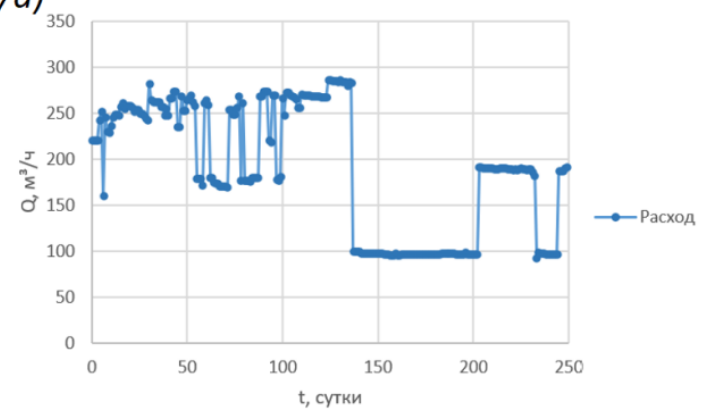

Рис. 2. Временные диаграммы температуры и расхода хладоносителя в замораживающих контурах для стволов № $1($ a, б) u № $2($ ( , г)

Fig. 2. Time diagrams of the temperature and flow rate of the coolant in the freezing circuits for shaft no. $1(a, b)$ and shaft no. $2(c, d)$ 

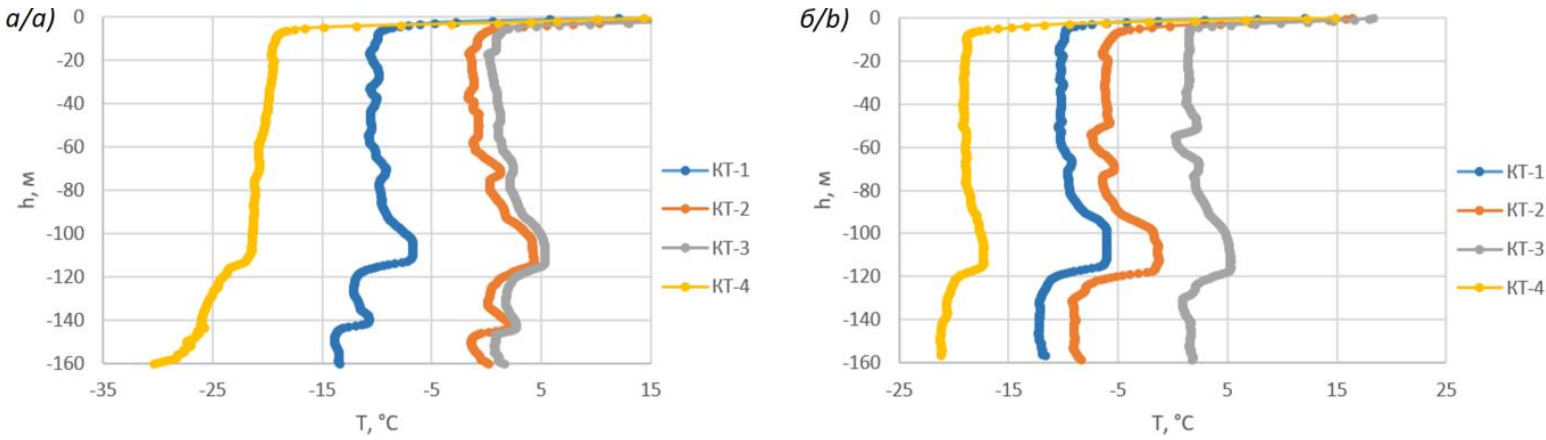

Pис. 3. Эпюры температур в КТ скважинах ствола № 1 (а) и ствола № 2 (б) в момент времени 100 суток Fig. 3. Temperatures in control boreholes vs depth; simulation time is 100 days; a) shaft no. 1; b) shaft no. 2

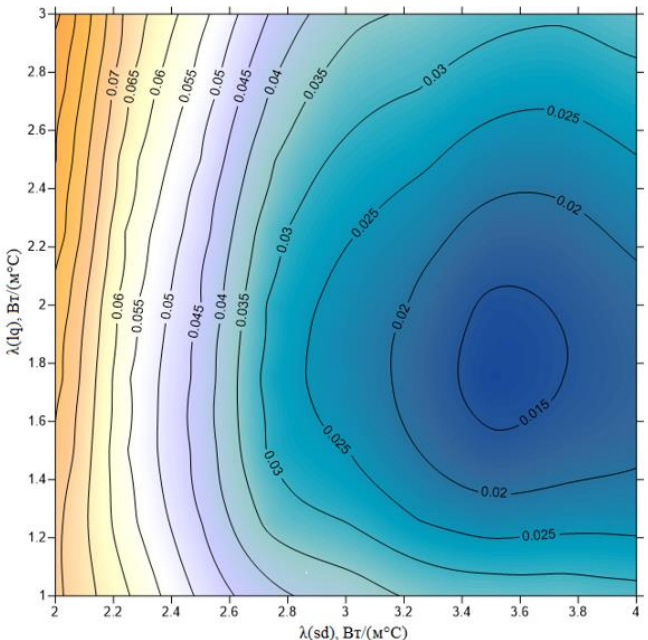

(a/a) $t_{\text {end }}=25$ cyт.

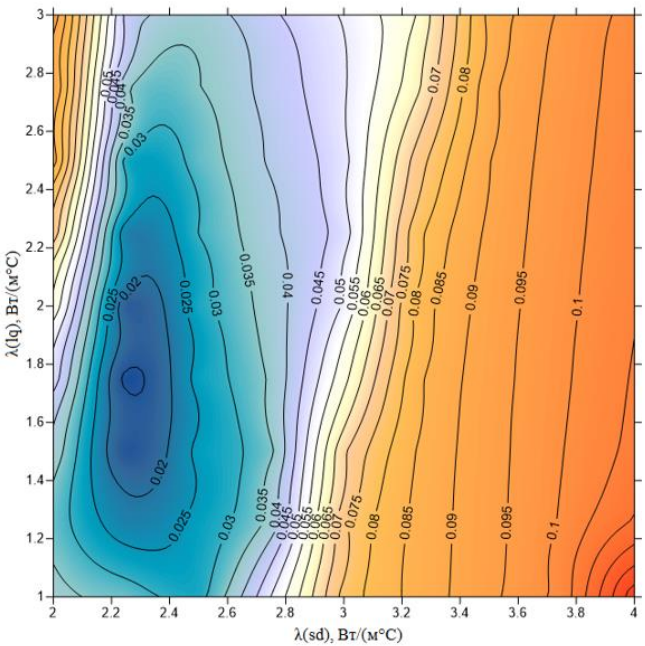

$(\mathrm{B} / \mathrm{c}) t_{\text {end }}=100$ сут.

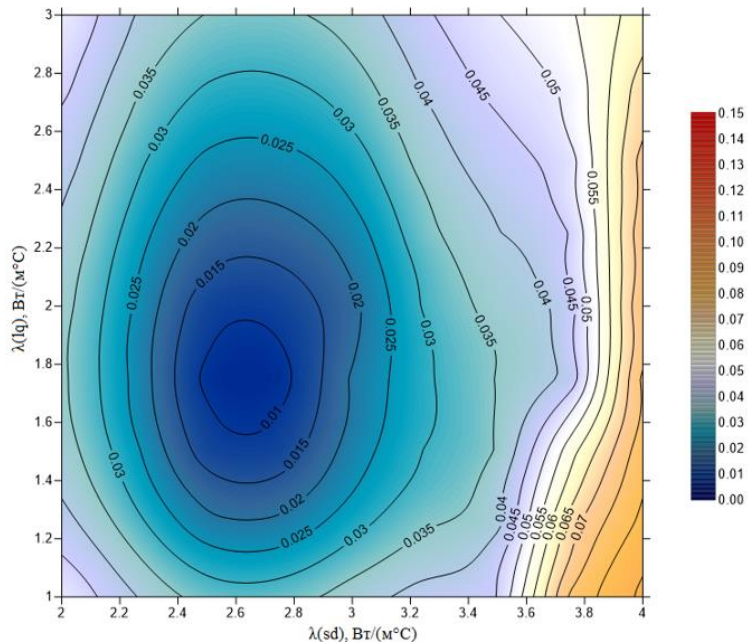

$(\sigma / \mathrm{b}) t_{\text {end }}=50$ cyт.

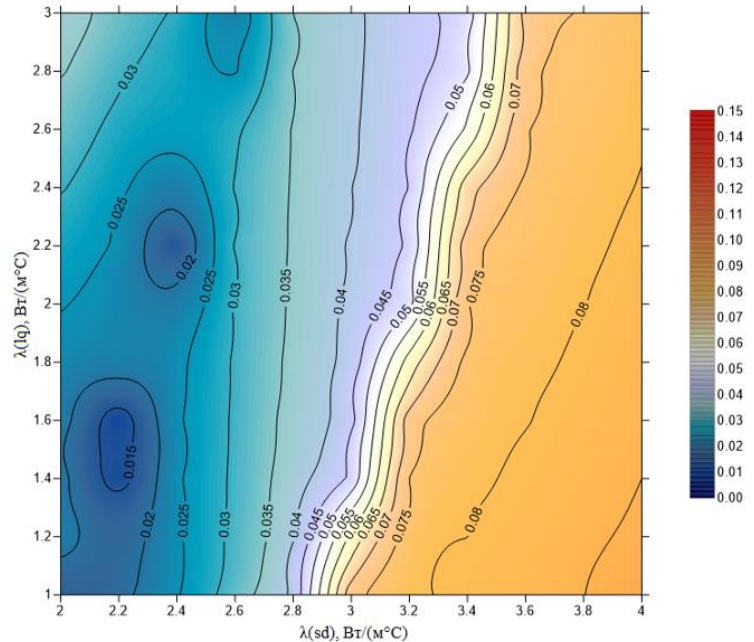

$(\Gamma / \mathrm{d}) t_{\text {end }}=150$ сут.

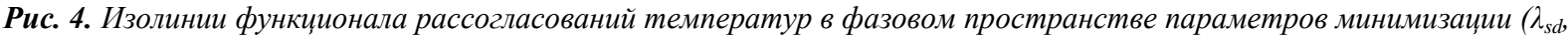
$\lambda_{\text {lq) }}$ при различных периодах замораживания для слоя мела, ствол № 1

Fig. 4. Isolines of the functional of temperature mismatch in the phase space of the minimization parameters $\left(\lambda_{\text {sd }}\right.$, $\left.\lambda_{\text {lq }}\right)$ at different freezing periods for the chalk layer, shaft no. 1 


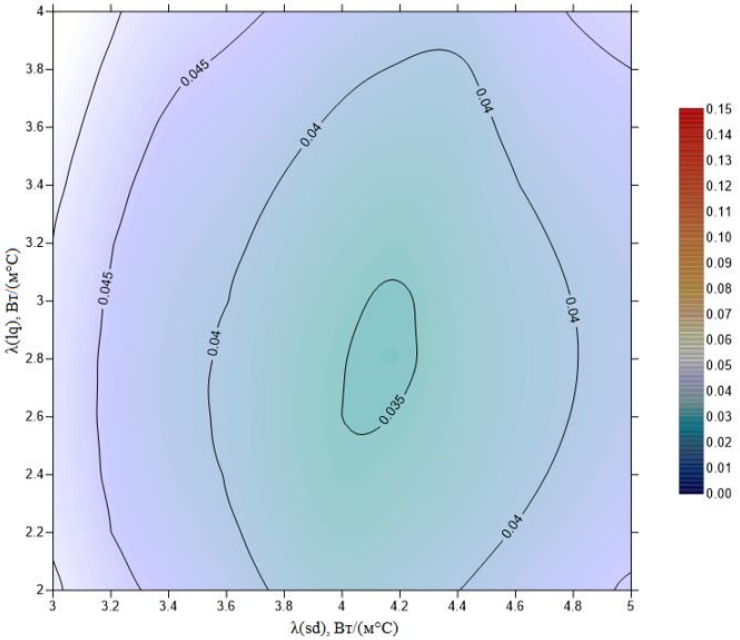

(a/a) $t_{\text {end }}=25$ cyт.

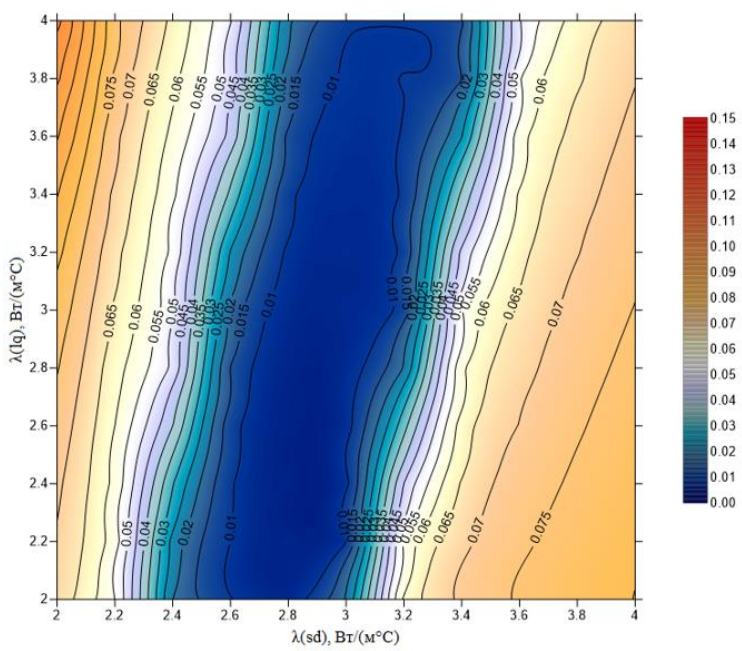

$(\mathrm{B} / \mathrm{c}) t_{\text {end }}=100$ сут.

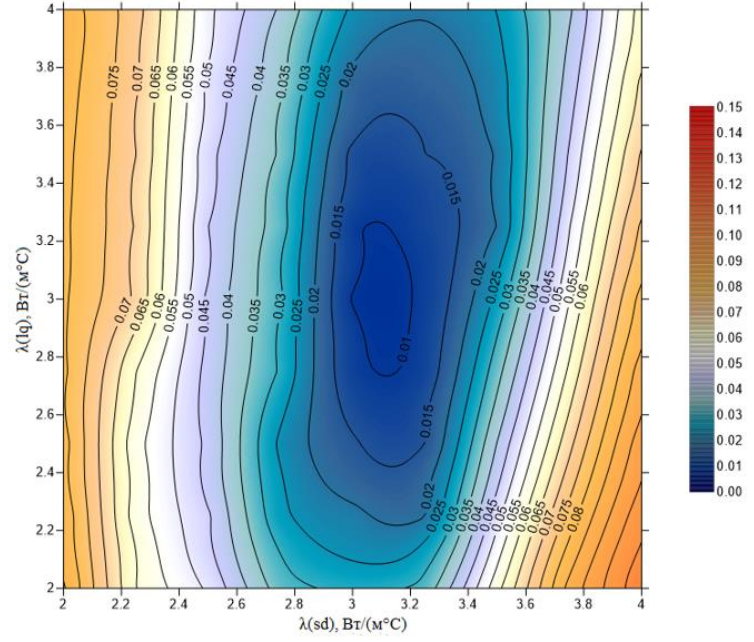

$(\sigma / \mathrm{b}) t_{\text {end }}=50$ cyт.

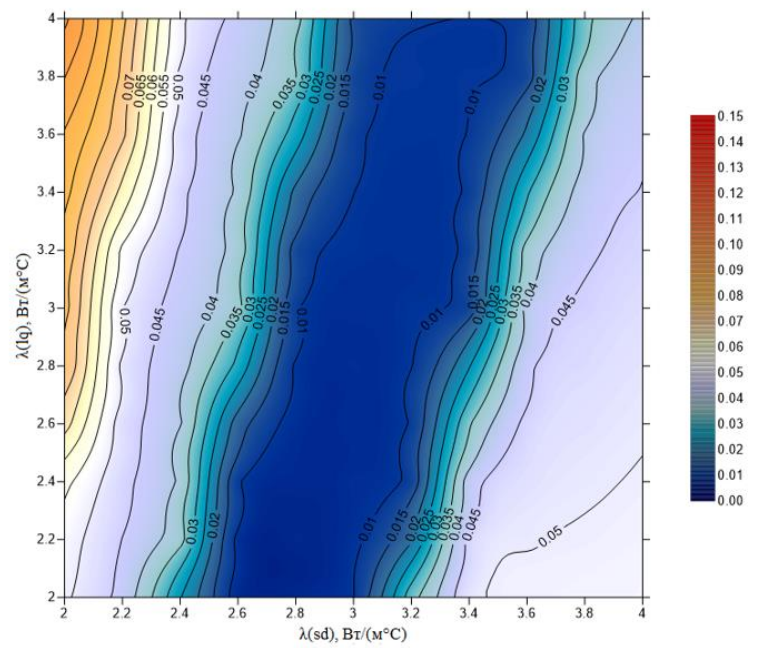

$(\Gamma / \mathrm{d}) t_{\text {end }}=150$ сут.

Рис. 5. Изолинии функиионала рассогласований температур в фазовом пространстве параметров минимизации $\left(\lambda_{\text {sd }}\right.$, $\lambda_{\text {lq }}$ ) при различных периодах замораживания для слоя песка, ствол № 1

Fig. 5. Isolines of the functional of temperature mismatch in the phase space of the minimization parameters $\left(\lambda_{s d}, \lambda_{l q}\right)$ at different freezing periods for the sand layer, shaft no. 1

В целом для всех четырех рассмотренных случаев ( 2 ствола и 2 слоя пород) получена схожая качественная картина изменения положения и формы минимума функционала $I$. На начальном промежутке времени с момента запуска системы замораживания $(0-50$ суток) минимум единственный, но его положение постепенно изменяется с течением времени (смещается справа налево). В промежуток времени 50-100 суток происходит изменение формы минимума из точки в линию. Положение линии в последующие моменты времени не изменяется существенным образом (исследовались времена до 250 суток с момента начала замораживания).

На некоторых графиках (рис. 4, г, 6, г) вместо линии минимумов присутствуют несколько локальных минимумов, лежащих на одной линии. Это связано с особенностями интерполяции двумерного поля функционала $I$ по ограниченному количеству вычисленных дискретных точек (сетка 9 на 9 точек).
Количественный анализ изолиний функционала $I$ позволил выявить следующие интересные особенности. Перемещение минимума функционала на начальном промежутке времени 0-50 суток для обоих слоев пород происходит практически параллельно оси абсцисс, т. е. в этот промежуток времени значение теплопроводности в зоне льда сильно зависит от времени. Следовательно, определение значения теплопроводности в зоне льда по данным скважинной термометрии на этом промежутке времени может оказаться недостоверным. Помимо этого, положения минимума функционала $I$ на начальном промежутке времени для обоих слоев пород различны для разных стволов, как по оси абсцисс, так и по оси ординат. Особенно ярко это проявляется для малых времен (25 суток, рис. $4, a$ и $6, a$ ). Вероятно, это связано с сильным влиянием факторов неоднородности пород, погрешностью данных инклинометрии и прочими неучтенными в модели факторами. 


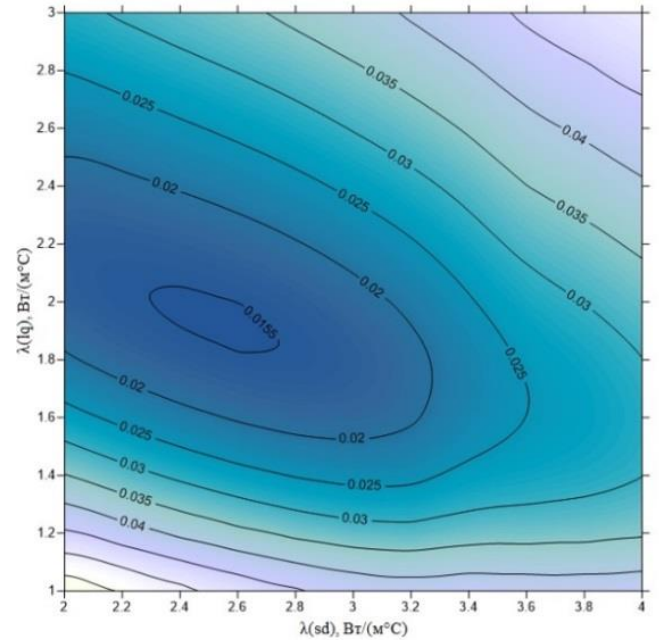

(a/a) $t_{\text {end }}=25$ cyт.

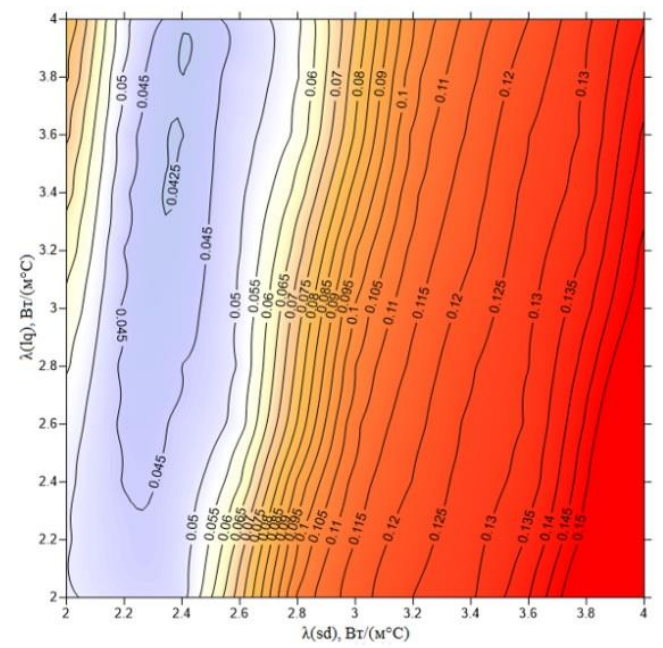

$(\mathrm{B} / \mathrm{c}) t_{\text {end }}=100$ сут.

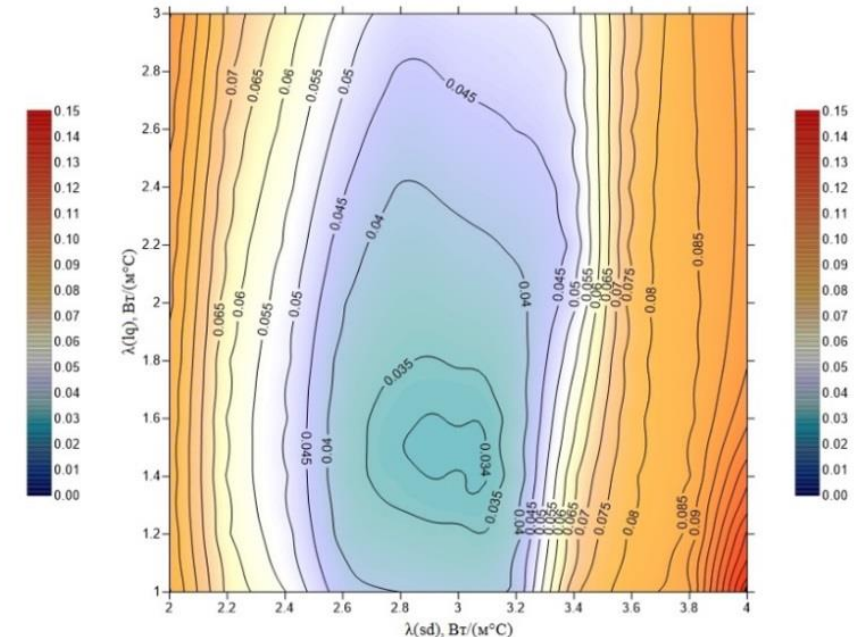

$(\sigma / b) t_{\text {end }}=50$ сут.

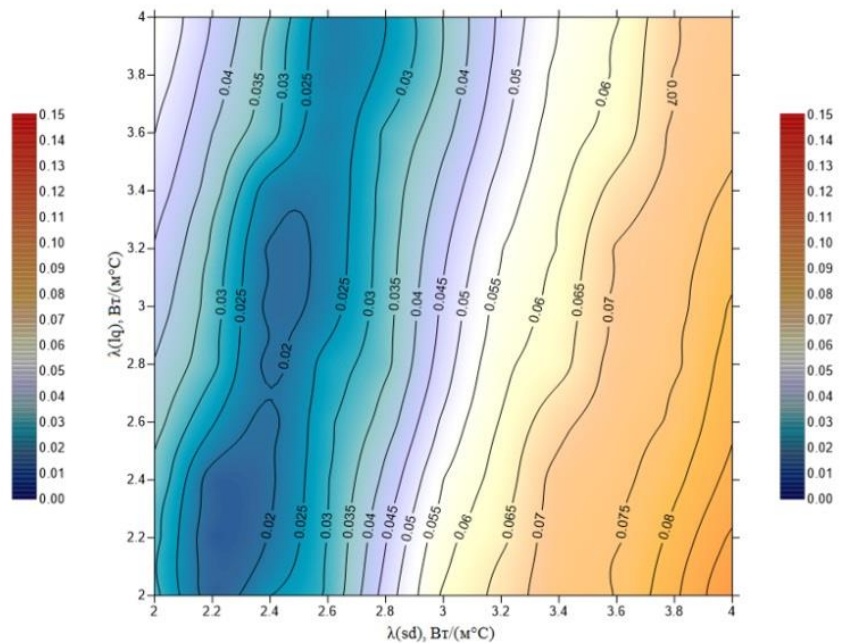

(г/d) $t_{\text {end }}=150$ сут.

Рис. 6. Изолинии функционала рассогласований температур в фазовом пространстве параметров минимизации $\left(\lambda_{s d}\right.$, $\lambda_{\text {Iq }}$ при различных периодах замораживания для слоя мела, ствол № 2

Fig. 6. Isolines of the functional of temperature mismatch in the phase space of the minimization parameters $\left(\lambda_{s d}, \lambda_{l q}\right)$ at different freezing periods for the chalk layer, shaft no. 2

Для времен моделирования более 100 суток положения линий минимумов функционала для разных стволов примерно совпадают и у мела, и у песка. Угол наклона линии минимумов функционала для мела варьируется в диапазоне от 75 до $84^{\circ}$, в то время как угол наклона линии минимумов функционала для песка варьируется в диапазоне от 73 до $81^{\circ}$. Это указывает на то, что при таких временах решение задачи Стефана намного более чувствительно к изменению теплопроводности в зоне льда, чем в зоне охлаждения. Также это указывает на то, что из решения обратной задачи Стефана при больших временах моделирования невозможно корректно определить одновременно теплопроводности в зонах льда и охлаждения.

\section{Анализ результатов моделирования}

Полученные закономерности изменения положений и формы минимума функционала (10) были также проанализированы на качественном уровне с по- мощью упрощенной модели теплового баланса в одномерном случае. Для простоты предполагалось, что в породном массиве имеется граница фазового перехода $\gamma$, разделяющая зону льда и охлаждения. В этом случае уравнение баланса теплоты для некоторого малого участка этой границы имеет вид:

$$
\left.\lambda^{(s d)} \frac{\partial T}{\partial r}\right|_{\gamma^{-}}-\left.\lambda^{(l q)} \frac{\partial T}{\partial r}\right|_{\gamma^{+}}=\rho L w \frac{d R}{d t},
$$

где $r$ - координата вдоль нормали к границе фазового перехода $\gamma, \mathrm{m} ; R$ - координата, характеризующая положение границы фазового перехода, м; индекс «+» указывает на то, что выражение записывается для области справа от границы (зона охлаждения), а индекс «-» - слева от границы (зона льда).

Выражение (11) представляет собой граничное условие на фронте фазового перехода в классической одномерной постановке задачи Стефана [20, 25]. Первое слагаемое слева в (11) характеризует теплоотток к 
замораживающей колонке, второе - земные теплопритоки. Их разница приводит к перемещению положения $R$ фронта фазового перехода и росту ЛПО.

Распределения температуры слева и справа от фронта фазового перехода $\gamma$ упрощенно может быть представлено с использованием одномерной модели, предложенной в [12]:

$$
\begin{array}{cl}
T_{1}=T_{f b}+\frac{T_{p h}-T_{f b}}{\ln \left(R / r_{f b}\right)} \ln \left(r / r_{f b}\right), & r_{f b}<r<R, \\
T_{2}=T_{0}+\frac{T_{p h}-T_{0}}{\ln \left(R / R_{0}\right)} \ln \left(r / R_{0}\right), \quad R<r<R_{0}
\end{array}
$$

Здесь $T_{p h}$ - температура фазового перехода, ${ }^{\circ} \mathrm{C}$; $r_{f b}$ - радиус замораживающей колонки, м; $R_{0}$ - радиус теплового влияния системы замораживания, м. Индекс «1» соответствует зоне льда, а индекс «2»- зоне охлаждения.

Выражения (12) и (13) соответствуют случаю единственной замораживающей скважины. Коорди- ната фронта фазового перехода $R$ и радиус теплового влияния $R_{0}$ являются функциями времени и других теплофизических свойств породного массива. Согласно $[1,12,25,26]$ они возрастают со временем пропорционально $t^{1 / 2}$.

Прежде всего, проведена оценка вклада каждого из слагаемых в уравнении (11). Так, в начальные моменты времени (стадия активного замораживания) толщина ЛПО мала, а температурный градиент максимален, вследствие чего первое слагаемое в (11) намного больше, чем второе. Это следует как из вида производных выражений (12) и (13) по радиальной координате, так и из результатов численного моделирования на двумерной модели (1)-(9) (рис. 7, a). Это приводит к тому, что рост ЛПО происходит преимущественно за счет первого слагаемого слева в (11). Если пренебречь вторым слагаемым слева, то решение задачи Стефана будет зависеть от отношения $\lambda^{(s d)} / w$. При этом зависимость решения от величины $\lambda^{(l q)}$ сохраняется и реализуется опосредованно через радиус теплового влияния.
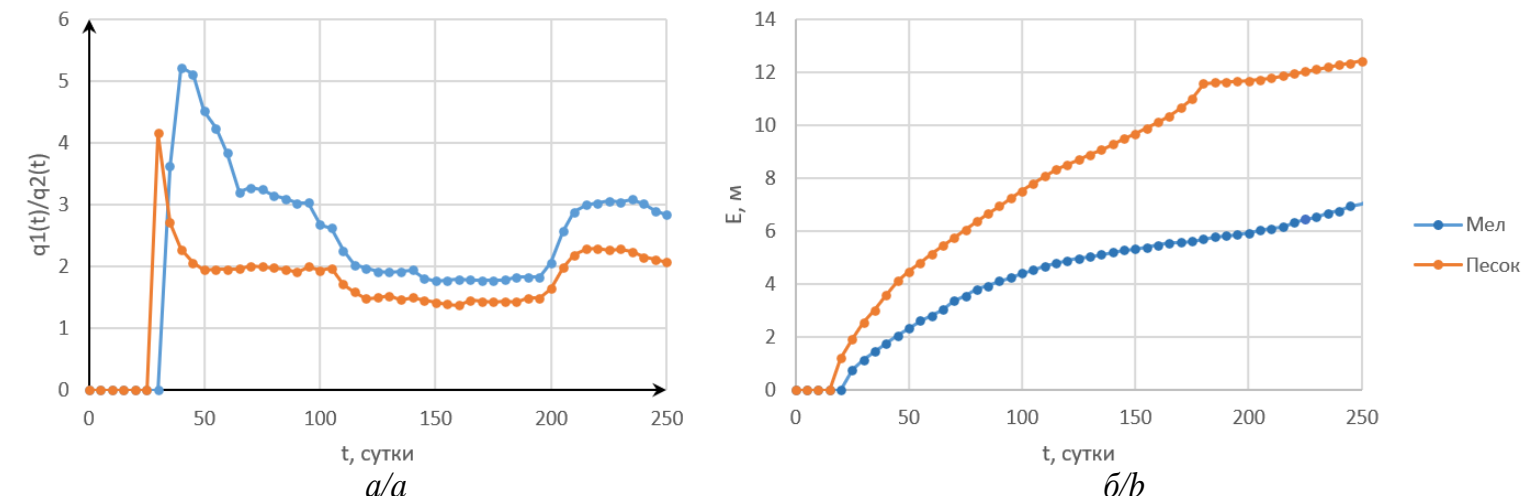

Рис. 7. Временные диаграммы отношения теплооттоков и теплопритоков к гранище ЛПО (а) и толщины ЛПО (б), ствол № 1

Fig. 7. Ratio of heat fluxes and heat inflows to the frozen wall boundary vs. time (a) and the frozen wall thickness vs. time (b), shaft no. 1

Затем в период пассивного замораживания ( $t>100$ суток), когда происходит замедление роста и/или поддержание ЛПО заданной толщины, тепловые потоки слева в (11) выравниваются и практически компенсируют друг друга. В этом случае величина $R$ изменяется слабо или же остается неизменной. Если в этом случае пренебречь правой частью (11) как наименьшим по абсолютной величине слагаемым, то нетрудно видеть, что решение будет зависеть от отношения теплопроводностей $\lambda^{(s d)} / \lambda^{(l q)}$. Именно такая картина наблюдается на рис. 4-6 при временах более 100 суток.

Проведенный анализ не объясняет причин временного изменения положения минимума функционала (10) на стадии активного замораживания. Поэтому дополнительно была проведена оценка чувствительности решения к погрешности измерений температуры, вносимой погрешностью данных скважинной инклинометрии. По опыту авторов настоящей работы погрешность определения смещения скважин, полученных из скважинной инклинометрии, может быть высока и превышать 0,5 м для глубин более 100 м [27, 28]. А с учетом того, что на начальном временном промежутке замораживания градиент температуры породного массива вблизи замораживающих скважин высокий, это может приводить к существенным погрешностям измерения температуры в КТ скважинах.

Если принять, что погрешность определения смещения КТ скважины от горизонтального положения по данным инклинометрии составляет $\Delta$ (м), то погрешность в определении температуры, определенная из (12) и (13), составит:

$$
\begin{gathered}
\Delta T_{1}=\frac{\partial T_{1}}{\partial r} \Delta=\left(T_{p h}-T_{f b}\right) \ln \left(\frac{r_{f b}}{R(t)}\right) \frac{\Delta}{r}, \\
\Delta T_{2}=\frac{\partial T_{2}}{\partial r} \Delta=\left(T_{p h}-T_{0}\right) \ln \left(\frac{R_{0}(t)}{R(t)}\right) \frac{\Delta}{r} .
\end{gathered}
$$

Использование той или иной формулы обусловлено тем, куда попадает КТ скважина - в зону льда или 
в зону охлаждения. В начальный промежуток времени до того, как граница фазового перехода достигла рассматриваемой КТ скважины, следует применять формулу (15), а далее - формулу (14). Функция (14) убывает с течением времени, в то время как функцию (15) можно считать приблизительно постоянной, т. к. согласно [12] соотношение между $R_{0}(t)$ и $R(t)$ не зависит от времени (случай единственной замораживающей скважины).

Граница фронта фазового перехода довольно быстро достигает все КТ скважины за исключением КТ-3, которые находятся на расстоянии более 2 м от контура замораживания. Об этом можно судить по временным зависимостям толщины ЛПО для ствола № 1 (рис. 7, б). Поэтому после 25-50 суток с момента начала замораживания следует применять формулу (14). В рамках этой формулы для условий строившихся стволов рудника Нежинского горнообогатительного комплекса погрешность определения температуры в КТ скважинах вследствие неточностей скважинной инклинометрии может быть приближенно оценена следующим образом:

$$
\Delta T_{1}=35 \cdot \ln \left(\frac{0,073}{1,073}\right) \frac{0,5}{1,073} \approx 13,4{ }^{\circ} \mathrm{C} .
$$

Здесь в качестве $r$ использовано расстояние от КТ скважины до ближайшей к ней замораживающей скважины - 1 м, величина радиуса фронта фазового перехода также принята равной 1 м. Если принять, что на всех КТ скважинах имеет место такая погрешность измерения температуры, то погрешность определения функционала (10) составит:

$$
\Delta I=\frac{\partial I}{\partial T^{(c)}} \Delta T^{(c)}=\frac{13,4}{35}=0,38 .
$$

Эта погрешность сопоставима со значениями функционала рассогласований (10), что следует из рис. 4-6, а потому может привести к существенному изменению положения минимума функционала. Если фактическое положение КТ скважины оказывается ближе к контуру замораживания, чем в математической модели с неправильно заданным смещением скважин по вертикали, то температурное влияние замораживающих скважин на КТ скважину в реальности произойдет быстрее, чем в модели. Это приведет к завышению теплопроводностей породного массива, что имело место в начальные моменты времени (рис. 4-6).

С течением времени погрешность (17) будет уменьшаться по логарифмическому закону (16) и, начиная с определенного момента, перестанет суще-

\section{СПИСОК ЛИТЕРАТУРЫ}

1. Трупак Н.Г. Замораживание горных пород при проходке стволов. - М.: Углетехиздат, 1954. - 895 с.

2. Шуплик М.Н. Специальные способы строительства подземных сооружений // Горный информационно-аналитический бюллетень (научно-технический журнал). - 2013. - № 1. C. $595-625$.

3. Правила безопасности при строительстве подземных сооружений ПБ 03-428-02 // утв. Постановлением Госгортехнадзора РФ от 02.11 .2001 № 49. - 167 c. ственным образом влиять на положение минимума функционала (10). Таким образом, гипотеза о погрешности скважинной инклинометрии объясняет временную динамику положения минимума функционала (10) на стадии активного замораживания, и только на этой стадии.

\section{Заключение}

В статье описаны проведенные исследования функционала рассогласования экспериментальноизмеренных и модельных температур в контрольнотермических скважинах. Показано, что минимум функционала рассогласования в определенных условиях меняется с течением времени или является неединственным. Это приводит к неоднозначности процедуры калибровки параметров математической модели тепловых процессов в замораживаемом породном массиве по данным скважинной термометрии.

В результате анализа условий возникновения неоднозначности получено, что на стадии активного замораживания возможно недостоверное определение теплопроводности в зоне льда из-за высокого градиента температуры породного массива вблизи контрольно-термических скважин и погрешности скважинной инклинометрии. На стадии пассивного замораживания возможно недостоверное определение обеих теплопроводностей (в зоне льда и в зоне охлаждения) вследствие того, что в данном промежутке времени решение прямой задачи Стефана зависит преимущественно от их соотношения.

В целом можно сделать вывод, что калибровка теплофизических параметров породного массива при его искусственном замораживании должна осуществляться на основании анализа временной зависимости положения и формы минимума функционала рассогласования температур в контрольно-термических скважинах. Определение теплофизических свойств породного массива по данным скважинной термометрии для отдельных моментов времени, скорее всего, окажется недостоверным.

В статье не исследовались другие возможные способы однозначного определения теплофизических свойств породного массива, например, применение других методов регуляризации обратной задачи Стефана (по методу А.Н. Тихонова), других способов вычисления функционала рассогласований. Данные вопросы являются предметом дальнейших исследований авторов статьи.

Исследование выполнено при финансовой поддержке РНФ в рамках научного проекта № 17-11-01204.

4. ВСН 189-78. Инструкция по проектированию и производству работ по искусственному замораживанию грунтов при строительстве метрополитенов и тоннелей. - М.: Минтрансстрой, 1978. $-117 \mathrm{c}$

5. Intellectual monitoring of artificial ground freezing in the fluidsaturated rock mass / I. Panteleev, A. Kostina, M. Zhelnin, O. Plekhov, L. Levin // Procedia Structural Integrity. - 2017. V. 5. - P. 492-499.

6. Левин Л.Ю., Семин М.А., Паршаков О.С. Совершенствование методов прогнозирования состояния ледопородного огражде- 
ния строящихся шахтных стволов с использованием распределенных измерений температуры в контрольных скважинах // Записки Горного института. - 2019. - Т. 237. - С. 268-274.

7. Применение искусственного замораживания грунтов при сооружении межтоннельной сбойки Серебряноборских тоннелей / И.Н. Тараненко, К.П. Никифоров, В.Н. Киселев, Е.А. Депланьи // Метро и тоннели. - 2008. - №. 2. - С. 20-23.

8. Thermal behavior in cross-passage construction during artificial ground freezing: case of Harbin Metro Line / Z. Li, J. Chen, M. Sugimoto, C. Mao // Journal of Cold Regions Engineering. 2020. - V. 34. - № 3. - art. no. 05020002.

9. Numerical simulation and measurement analysis of the temperature field of artificial freezing shaft sinking in Cretaceous strata / Z. Yao, H. Cai, W. Xue, X. Wang, Z. Wang // AIP Advances. 2019. - V. 9. - № 2. - C. 025209.

10. Papakonstantinou S., Anagnostou G., Pimentel E. Evaluation of ground freezing data from the Naples subway // Proceedings of the Institution of Civil Engineers: Geotechnical Engineering. - 2013. V. 166. - № 3. - P. 280-298.

11. Modeling artificial ground freezing for construction of two tunnels of a metro station in Napoli (Italy) / A. Mauro, G. Normino, F. Cavuoto, P. Marotta, N. Massarotti // Energies. - 2020. V. 13. - № 5. - art. no. en13051272. DOI: 10.3390/en13051272

12. Хакимов Х.Р. Вопросы теории и практики искусственного замораживания грунтов. - М.: Изд-во Академии наук СССР, 1957. $-191 \mathrm{c}$.

13. Artificial ground freezing: a review of thermal and hydraulic aspects / M.A. Alzoubi, M. Xu, F.P. Hassani, S. Poncet, A. Sasmito // Tunnelling and Underground Space Technology. - 2020. V. 104. - art. no. 103534

14. Fan W., Yang P. Ground temperature characteristics during artificial freezing around a subway cross passage // Transportation Geotechnics. - 2019. - V. 20. - art. no. 100250.

15. Artificial ground freezing to excavate a tunnel in sandy soil. Measurements and back analysis / G. Russo, A. Corbo, F. Cavuoto, S. Autuori // Tunnelling and Underground Space Technology. 2015. - V. 50. - P. 226-238.

16. Viggiani G.M.B., De Sanctis L. Geotechnical aspects of underground railway construction in the urban environment: the examples of Rome and Naples // Geological Society Engineering Geology Special Publication. - 2009. - V. 22. - № 1. - P. 215-240. DOI: $10.1144 /$ EGSP22.18

17. Левин Л.Ю., Семин М.А., Зайцев А.В. Калибровка теплофизических свойств породного массива при моделировании формирования ледопородного ограждения строящихся шахт- ных стволов // Физико-технические проблемы разработки полезных ископаемых. - 2019. - № 1. - С. 172-184.

18. Численное решение обратной задачи определения объемной теплоемкости породного массива в процессе искусственного замораживания / М.С. Желнин, О.А. Плехов, М.А. Семин, Л.Ю. Левин // Вестник Пермского национального исследовательского политехнического университета. Механика. 2017. - № 4. - С. 56-75.

19. Долгов О.А. Методика расчета процесса замораживания горных пород при проходке стволов шахт способом замораживания на большую глубину // Замораживание горных пород при проходке стволов шахт. - М.: Изд-во Академии наук СССР, 1961. - C. 9-64.

20. Myers T.G., Hennessy M.G., Calvo-Schwarzwälder M. The Stefan problem with variable thermophysical properties and phase change temperature // International Journal of Heat and Mass Transfer. 2020. - T. 149. - art. no. 118975

21. Самарский А.А., Моисеенко Б.Д. Экономичная схема сквозного счета для многомерной задачи Стефана // Журнал вычислительной математики и математической физики. - 1965. T. 5. - № 5. - C. 816-827.

22. Цытович Н.А. Механика мерзлых грунтов. - М.: Высш. школа 1973. $-448 \mathrm{c}$

23. Данилова Г.Н., Филаткин В.Н. Сборник задач по процессам теплообмена в пищевой и холодильной промышленности. М.: Пищевая промышленность, 1976. - 240 с.

24. Михеев М.А. Основы теплопередачи. - М.-Л.: ГЭИ, 1956. $390 \mathrm{c}$.

25. Карслоу Г., Егер Д. Теплопроводность твердых тел / пер. с англ. - М.: Наука, 1964. - 488 с.

26. Зайцев А.В. Научные основы расчета и управления тепловым режимом подземных рудников: дис. ... д-ра техн. наук. Пермь, 2019. - 247 с.

27. Паршаков О.С. Разработка автоматизированной системы термометрического контроля ледопородных ограждений: дис. ... канд. техн. наук. - Пермь, 2020. - 140 с.

28. Thermal Monitoring of frozen wall thawing after artificial ground freezing: case study of Petrikov potash mine / L. Levin, I. Golovatiy, A. Zaitsev, A. Pugin, M. Semin // Tunnelling and Underground Space Technology incorporating Trenchless Technology Research. - 2021. - V. 107. - art. no. 103685

Поступила 19.04.2021 2.

Информация об авторах

Семин М.A., кандидат технических наук, научный сотрудник отдела аэрологии и теплофизики, Горный институт УрО РАН.

Левин Л.Ю., доктор технических наук, заведующий отделом аэрологии и теплофизики, Горный институт УрО PAH.

Богомягков A.B., младший научный сотрудник лаборатории математического моделирования горнотехнических процессов, Горный институт УрО РАН.

Пугин А.В., кандидат технических наук, научный сотрудник отдела аэрологии и теплофизики, Горный институт УрО РАН. 
UDC 622.253 .3

\title{
ON THE AMBIGUITY OF INTERPRETATION OF THE TEMPERATURE FIELD OF THE FROZEN ROCK MASS USING BOREHOLE THERMOMETRY
}

\author{
Mikhail A. Semin 1 , \\ seminma@inbox.ru \\ Lev Yu. Levin 1 \\ aerolog_lev@mail.ru \\ Alexander V. Bogomyagkov ${ }^{1}$, \\ bavaerolog@gmail.com \\ Aleksey V. Pugin 1 , \\ lyosha.p@gmail.com \\ 1 Mining Institute of the Ural Branch of the Russian Academy of Sciences, \\ 78-a, Sibirskaya street, Perm, 614007, Russia.
}

The relevance. Sinking vertical mine shafts using artificial ground freezing requires controlling the state of the frozen wall formed around the shaft under construction. The most widespread and informative method of experimental control of the frozen wall state is borehole thermometry. The borehole thermometry data is used to adjust the parameters of the model (thermophysical properties of rocks) to recreate the temperature field in the entire volume of the frozen rock mass by means of mathematical modeling. Adjustment of the model parameters under certain conditions can lead to ambiguity in determining the model parameters, the reason for which is currently not studied. The main aim is to study the conditions for ambiguity occurrence in the calculated thermophysical properties of the rock mass as a result of the adjusting the parameters of the model according to the measurement data in the control boreholes.

The object of the research is a frozen water-saturated rock mass around two mine shafts of the potash mine of the Nezhinsky mining and processing complex under construction.

Research methods included the collection and processing of borehole thermometry data, the formulation of a mathematical model of heat transfer in the frozen rock mass, the numerical solution of the direct and inverse Stefan problems and the theoretical interpretation of the mismatch between the measured and calculated temperatures of the rocks.

Results. We studied the mismatch between the measured and numerically calculated temperatures in the control boreholes on the phase plane of the adjusted parameters of the model - the thermal conductivities of frozen and unfrozen rocks. It is shown that the minimum of the mismatch functional under certain conditions moves over time or is not unique. The analysis of the arising ambiguity is carried out on the basis of a simplified mathematical model of the heat balance at the boundary of the phase transition front. It was found that at the ice growing stage, an unreliable determination of thermal conductivity in the frozen rock is possible due to the high temperature gradient in the rock mass near the control boreholes and the error of borehole inclinometry. At the ice holding stage, an unreliable determination of both thermal conductivities is possible, since the solution of the problem depends mainly on their ratio.

\section{Key words:}

Artificial freezing of rocks, frozen wall, control boreholes, inverse Stefan problem, mathematical modeling, thermal conductivity of rocks.

The research was financially supported by the Russian Science Foundation within the scientific project no. 17-11-01204.

\section{REFERENCES}

1. Trupak N.G. Zamorazhivanie gornykh porod pri prokhodke stvolov [Freezing of rocks during shaft sinking]. Moscow, Ugletekhizdat Publ., 1954. 895 p

2. Shuplik M.N. Special methods of construction of underground structures. Mining information and analytical bulletin (scientific and technical journal), 2013, no. 1, pp. 595-625. In Rus.

3. Pravila bezopasnosti pri stroitelstve podzemnykh sooruzheniy $P B$ 03-428-02 [Safety rules for the construction of underground structures]. Moscow, Gosgortekhnadzor RF Publ., 2001. 167 p.

4. VSN 189-78. Instruktsiya po proektirovaniyu i proizvodstvu rabot po iskusstvennomu zamorazhivaniyu gruntov pri stroitelstve metropolitenov $i$ tonneley [Instructions for the design and production of works on artificial freezing of soils during the construction of subways and tunnels]. Moscow, Mintransstroy Publ., 1978. 117 p.

5. Panteleev I., Kostina A., Zhelnin M., Plekhov O., Levin L. Intellectual monitoring of artificial ground freezing in the fluidsaturated rock mass. Procedia Structural Integrity, 2017, vol. 5, pp. 492-499.

6. Levin L.Yu., Semin M.A., Parshakov O.S. Improving methods of frozen wall state prediction for mine shafts under construction using distributed temperature measurements in test wells. Journal of
Mining Institute, 2019, vol. 237, pp. 268-274. DOI 10.31897/PML2019.3.268 In Rus.

7. Taranenko I.N., Nikiforov K.P., Kiselev V.N., Deplanyi E.A. The use of artificial soil freezing in the construction of an inter-tunnel linkage of the Serebryanoborsk tunnels. Metro and tunnels, 2008, no. 2, pp. 20-23. In Rus.

8. Li Z., Chen J., Sugimoto M., Mao C. Thermal behavior in crosspassage construction during artificial ground freezing: case of Harbin Metro Line. Journal of Cold Regions Engineering, 2020, vol. 34, no. 3, art.no. 05020002 .

9. Yao Z., Cai H., Xue W., Wang X., Wang Z. Numerical simulation and measurement analysis of the temperature field of artificial freezing shaft sinking in Cretaceous strata. AIP Advances, 2019, vol. 9 , no. 2, art. no. 025209 .

10. Papakonstantinou S., Anagnostou G., Pimentel E. Evaluation of ground freezing data from the Naples subway. Proceedings of the Institution of Civil Engineers: Geotechnical Engineering, 2013, vol. 166 , no. 3, pp. 280-298.

11. Mauro A., Normino G., Cavuoto F., Marotta P., Massarotti N. Modeling artificial ground freezing for construction of two tunnels of a metro station in Napoli (Italy). Energies, 2020, vol. 13, no. 5, art. no. en13051272. DOI: $10.3390 / \mathrm{en} 13051272$. 
12. Khakimov H.R. Voprosy teorii i praktiki iskusstvennogo zamorazhivaniya gruntov [Issues of the theory and practice of artificial soil freezing]. Moscow, Akademiya nauk SSSR Publ., 1957. $191 \mathrm{p}$

13. Alzoubi M.A., Xu M., Hassani F.P., Poncet S., Sasmito A. Artificial ground freezing: a review of thermal and hydraulic aspects. Tunnelling and Underground Space Technology, 2020, vol. 104, art. no. 103534 .

14. Fan W., Yang P. Ground temperature characteristics during artificial freezing around a subway cross passage. Transportation Geotechnics, 2019, vol. 20, art. no. 100250 .

15. Russo G., Corbo A., Cavuoto F., Autuori S. Artificial ground freezing to excavate a tunnel in sandy soil. Measurements and back analysis. Tunnelling and Underground Space Technology, 2015, vol. 50, pp. 226-238.

16. Viggiani G.M.B., De Sanctis L. Geotechnical aspects of underground railway construction in the urban environment: the examples of Rome and Naples. Geological Society Engineering Geology Special Publication, 2009, vol. 22, no. 1, pp. 215-240. DOI: 10.1144/EGSP22.18

17. Levin L.Y., Semin M.A. Zaitsev A.V. Adjustment of thermophysical rock mass properties in modeling frozen wall formation in mine shafts under construction. Journal of Mining Science, 2019. vol. 55, pp. 157-168. DOI: 10.1134/S1062739119015419

18. Zhelnin M.S., Plekhov O.A., Semin M.A., Levin L.Yu. Numerical solution for an inverse problem about determination of volumetric heat capacity of rock mass during artificial freezing. PNRPU Mechanics Bulletin, 2017, no. 4, pp. 56-75. DOI: 10.15593/perm.mech/2017.4.05

19. Dolgov O.A. Metodika rascheta protsessa zamorazhivaniya gornykh porod pri prokhodke stvolov shakht sposobom zamorazhivaniya na bolshuyu glubinu [Methodology for calculating the process of freezing rocks when driving mine shafts by freezing to a great depth]. Zamorazhivanie gornykh porod pri prokhodke stvolov shaht [Freezing of soils during shaft sinking]. Moscow, Akademiya nauk SSSR Publ., 1961. pp. 9-64.
20. Myers T.G., Hennessy M.G., Calvo-Schwarzwälder M. The Stefan problem with variable thermophysical properties and phase change temperature. International Journal of Heat and Mass Transfer, 2020, vol. 149, art. no. 118975 .

21. Samarskii A.A., Moiseyenko B. D. An economic continuous calculation scheme for the stefan multidimensional problem. USSR Computational Mathematics and Mathematical Physics, 1965, vol. 5, no. 5, pp. 43-58. In Rus.

22. Cytovich N.A. Mekhanika merzlykh gruntov [Mechanics of frozen soils]. Moscow, Vysshaya shkola Publ., 1973. 448 p.

23. Danilova G.N., Filatkin V.N. Sbornik zadach po protsessam teploobmena $v$ pishchevoy $i$ kholodilnoy promyshlennosti [Collection of problems on the processes of heat exchange in the food and refrigeration industry]. Moscow, Pishchevaya promyshlennost Publ., 1976. $240 \mathrm{p}$

24. Miheev M.A. Osnovy teploperedachi [Heat transfer basics]. Moscow, Leningrad, GEI Publ., 1956. 390 p.

25. Carslaw H.S., Jaeger J.C. Conduction of heat in solids. Moscow, Nauka Publ., 1964. 488 p.

26. Zaitsev A.V. Nauchnye osnovy rascheta $i$ upravleniya teplovym rezhimom podzemnykh rudnikov. Dis. Dokt. nauk [Scientific basis for calculating and controlling the thermal regime of underground mines]. Perm, 2019. 247 p.

27. Parshakov O.S. Razrabotka avtomatizirovannoy sistemy termometricheskogo kontrolya ledoporodnykh ograzhdeniy. Dis. Kand. nauk [Development of an automated system for thermometric control of frozen wall]. Perm, 2020. $140 \mathrm{p}$.

28. Levin L., Golovatiy I., Zaitsev A., Pugin A., Semin M. Thermal monitoring of frozen wall thawing after artificial ground freezing: case study of Petrikov potash mine. Tunnelling and Underground Space Technology, 2021, vol. 107, art. no. 103685.

Received: 19 April 2021.

\section{Information about the authors}

Mikhail A. Semin, Cand. Sc., researcher, Mining Institute of the Ural Branch of the Russian Academy of Sciences.

Lev Yu. Levin, Dr. Sc., head of the Department of Aerology and Thermophysics, Mining Institute of the Ural Branch of the Russian Academy of Sciences.

Alexander V. Bogomyagkov, junior researcher, Mining Institute of the Ural Branch of the Russian Academy of Sciences.

Aleksey V. Pugin, Cand. Sc., researcher, Mining Institute of the Ural Branch of the Russian Academy of Sciences. 